\title{
Hemofiltration in ex vivo lung perfusion-a study in experimentally induced pulmonary edema
}

Tobias Nilsson, MD, ${ }^{\mathrm{a}, \mathrm{b}}$ Christoffer Hansson, MS, ${ }^{\mathrm{c}, \mathrm{d}}$ Andreas Wallinder, MD, PhD, ${ }^{\mathrm{c}, \mathrm{d}}$

Carl-Johan Malm, MD, ${ }^{\mathrm{c}, \mathrm{d}}$ Martin Silverborn, MD, PhD, ${ }^{\mathrm{c}, \mathrm{d}}$ Sven-Erik Ricksten, MD, PhD, ${ }^{\mathrm{a}, \mathrm{b}}$ and Göran Dellgren, $\mathrm{MD}, \mathrm{PhD}^{\mathrm{c}, \mathrm{d}, \mathrm{e}}$

\begin{abstract}
Objectives: Ex vivo lung perfusion (EVLP) can potentially reduce pulmonary edema. In a pig model with induced pulmonary edema, we evaluated the effect of hemofiltration (HF) during EVLP on lung function, perfusate oncotic pressure, and lung weight.

Methods: In anesthetized pigs $(\mathrm{n}=14)$, pulmonary edema was induced by a balloon in the left atrium, combined with crystalloid infusion $(20 \mathrm{~mL} / \mathrm{kg})$, for 2 hours. The lungs were harvested, stored cold for 2 hours, and randomized to EVLP, with or without a hemofilter (HF and noHF groups, respectively, $\mathrm{n}=7$ for each). EVLP was performed with cellular perfusate at a hematocrit of $10 \%$ to $15 \%$. Oncotic pressure, lung performance, and weight were measured before and after 180 minutes of EVLP reconditioning with or without HF.
\end{abstract}

Results: After in vivo induction of edema, arterial oxygen tension $\left(\mathrm{PaO}_{2}\right) /$ inspired oxygen fraction $\left(\mathrm{FIO}_{2}\right)$, and compliance decreased by $63 \%$ and $16 \%$, respectively. $\mathrm{PaO}_{2} / \mathrm{FIO}_{2}$ was considerably improved at first evaluation ex vivo in both groups. HF increased oncotic pressure by $43 \%$ and decreased lung weight by $15 \%$. The effects were negligible in the noHF group. Compliance decreased in both groups during reconditioning, although less so in the HF group $(P<.05) . \mathrm{PaO}_{2} /$ $\mathrm{FIO}_{2}$, shunt fraction, and oxygen saturation remained unchanged in both groups. Pulmonary flow index decreased in both groups, and was partially reversed by nitroglycerin. Dorsal atelectatic consolidations were seen in both groups.

Conclusions: In this lung-edema model, EVLP reconditioning with hyperoncotic solution did not affect the degree of lung edema. HF during EVLP increased perfusate oncotic pressure, decreased lung weight with beneficial effects on compliance, but did not improve lung oxygenation capacity. (J Thorac Cardiovasc Surg 2016;151:570-5)

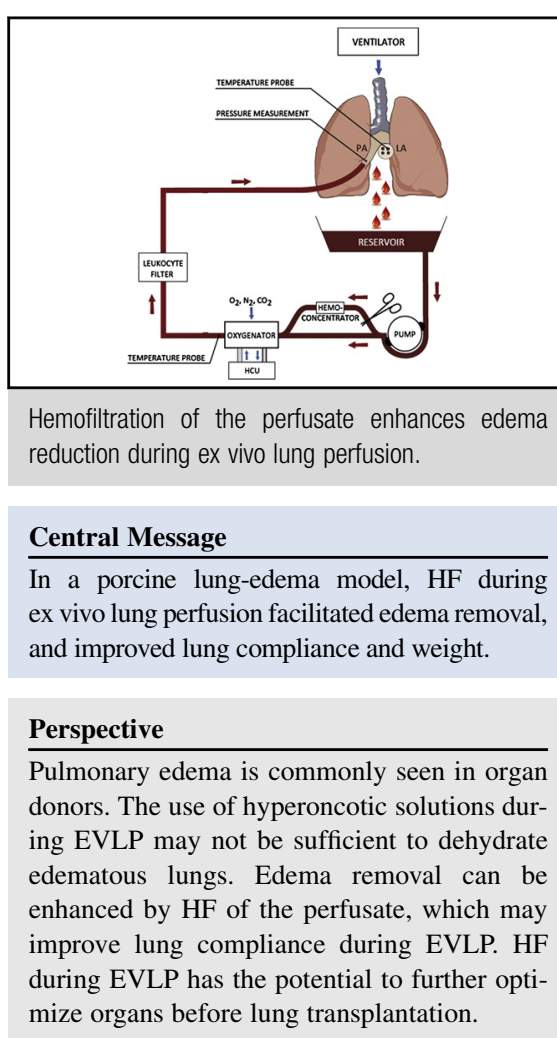

See Editorial Commentary page 576.

See Editorial page 315 .
From the a Department of Cardiothoracic Anesthesia and Intensive Care, Sahlgrenska University Hospital; ${ }^{\mathrm{b}}$ Department of Anesthesiology and Intensive Care Medicine, Institute of Clinical Sciences, Sahlgrenska Academy, University of Gothenburg; ${ }^{\mathrm{c}}$ Department of Cardiothoracic Surgery, Sahlgrenska University Hospital; ${ }^{\mathrm{d}}$ Department of Molecular and Clinical Medicine, Institute of Medicine, Sahlgrenska Academy, University of Gothenburg; and ${ }^{\mathrm{e}}$ Transplant Institute, Sahlgrenska Academy, University of Gothenburg, Gothenburg, Sweden.

This work was supported by grants from the Swedish Heart-Lung Foundation (grant number 20130497); the Jan Elgqvist Foundation; and a Strategic Research Grant of the Sahlgrenska University Hospital (grant number 77330).

Received for publication Feb 16, 2015; revisions received May 14, 2015; accepted for publication June 3, 2015; available ahead of print July 26, 2015.

Address for reprints: Göran Dellgren, MD, PhD, Department of Cardiothoracic Surgery and Transplant Institute, Sahlgrenska University Hospital, SE-413 45 Gothenburg, Sweden (E-mail: goran.dellgren@vgregion.se).

0022-5223/\$36.00

Copyright (c) 2016 by The American Association for Thoracic Surgery

http://dx.doi.org/10.1016/j.jtcvs.2015.06.046
丹 Supplemental material is available online.

Ex vivo lung perfusion (EVLP) of initially rejected donor lungs has, since its clinical introduction, ${ }^{1}$ in 2007 , been shown to increase the potential number of organs available for transplantation. ${ }^{2-4}$ Pulmonary edema often develops in organ donors. EVLP of the donor lung with a hyperoncotic perfusate can, in theory, reduce pulmonary edema. However, the oncotic pressure of the perfusate, and hence the edema-reducing property, would be expected to decline over time, as the oncotic pressures of the perfusate and interstitial space equilibrates. An intermittent 


$$
\begin{aligned}
& \text { Abbreviations and Acronyms } \\
& \mathrm{EVLP}=\text { ex vivo lung perfusion } \\
& \mathrm{FIO}_{2}=\text { inspired fraction of oxygen } \\
& \mathrm{HF}=\text { hemofiltration } \\
& \text { noHF }=\text { no hemofiltration } \\
& \mathrm{PO}_{2}=\text { oxygen tension } \\
& \text { PVRI }=\text { pulmonary vascular resistance index } \\
& \Delta \mathrm{Po}_{2}=\text { difference between left atrial oxygen } \\
& \text { tension and pulmonary artery oxygen } \\
& \text { tension }
\end{aligned}
$$

replacement of part of the perfusate has been proposed as a method to counteract the diminishing gradient, but the effect is yet to be proven..$^{5}$ As an alternative, we introduced hemofiltration (HF) of the perfusate during EVLP, to maintain a high oncotic pressure. ${ }^{6}$ We investigated, in a porcine model of pulmonary edema, the effects of HF during EVLP, on lung performance, lung weight, and oncotic pressures.

\section{METHODS}

\section{Animal Model}

The Animal Ethical Committee of the University of Gothenburg approved the study. Twenty-two animals were included in the study and received care in compliance with the European Convention for the Protection of Vertebrate Animals Used for Experimental and Other Scientific Purposes (1986), the Principles of Laboratory Animal Care formulated by the National Society for Medical Research, and the Guide for the Care and Use of Laboratory Animals from the National Institutes of Health.

All animals were anesthetized and intubated through the trachea. Anesthesia was maintained with buprenorphine and isoflurane. Volumecontrolled ventilation was performed at a tidal volume of $10 \mathrm{~mL} / \mathrm{kg}$, with no positive end-expiratory pressure, and an inspired fraction of oxygen $\left(\mathrm{FiO}_{2}\right)$ of 0.5 . The ventilation rate was adjusted to an end-tidal $\mathrm{CO}_{2}$ of 5 to $5.5 \mathrm{kPa}$.

\section{Study Design}

Twenty-two pigs were included in the study. All animals were subjected to EVLP. Sixteen of these animals were subjected to induction of pulmonary edema in vivo, before EVLP, and 6 animals (controls) were not. In the lung-edema group, the animals were randomized, in blocks of 4 , to the HF group, or the no HF (noHF) group of the perfusate during EVLP (Figure 1).

\section{Pulmonary Edema Model}

An arterial catheter was placed in the right femoral artery, and a SwanGanz catheter (Edwards Lifesciences, Irvine, Calif) was introduced via the right external jugular vein. Correct positioning of the latter was verified by inspection of the pressure waveform, during introduction and advancement to wedge position. After sternotomy, the pericardium was opened, and a balloon-tipped catheter was introduced, via a small incision in the left atrial appendage, into the left atrium, and secured into place with a purse string suture.

A crystalloid infusion was initiated at $20 \mathrm{~mL} / \mathrm{kg}$ body weight per hour. The left atrial balloon was inflated gradually to a pulmonary capillary wedge pressure of 25 to $30 \mathrm{~mm} \mathrm{Hg}$, which was maintained for 2 hours. Arterial blood gases, and respiratory and circulatory variables were measured and recorded before and after induction of pulmonary edema. The pigs were exsanguinated to a cell saver, and the blood was processed for use during EVLP.

\section{Lung Harvesting}

In all animals, the lungs were subjected to antegrade and retrograde perfusion with 4 liters of Perfadex (XVIVO Perfusion AB, Gothenburg, Sweden), with additives as previously described. ${ }^{7}$ The lungs were harvested, weighed, and stored in cold Perfadex at $8^{\circ} \mathrm{C}$ for 2 hours. Thereafter, they were again weighed and subjected to retrograde perfusion with an additional 1 liter of Perfadex.

\section{Ex Vivo Lung Perfusion}

Ex vivo lung perfusion was performed (Figure 2) with the Conformite Européenne-marked Vivoline LS1 (Vivoline Medical AB, Lund, Sweden) primed with 2 liters Steen solution (XVIVO Perfusion AB), red blood cells (salvaged from the donor pig) to a hematocrit of $10 \%$ to $15 \%$, as well as meropenem and heparin, as previously described. ${ }^{4}$

The lungs were prepared and connected to the EVLP device. After de-airing of the circuit, the lungs were rewarmed to $36^{\circ} \mathrm{C}$, with pulmonary flow allowed to increase gradually as temperature increased. Ventilation was initiated at $32^{\circ} \mathrm{C}$. At $36^{\circ} \mathrm{C}$, after lung recruitment, a first evaluation was performed, with measurements after 5 and 10 minutes in evaluation mode. A reconditioning phase of 180 minutes followed. In the $\mathrm{HF}$ group, the perfusate was ultrafiltrated to a total filtered volume of $500 \mathrm{~mL}$. The lungs were recruited every 60 minutes, during temporary arrest of perfusion, and arterial blood gases were measured, correcting base excess with $1 \mathrm{~mL}$ of trometamol for every unit below zero. A second evaluation followed, with measurements made at 5 and 10 minutes in evaluation mode. During both evaluation phases, pulmonary flow was changed to generate a pulmonary artery pressure of $25 \mathrm{~mm} \mathrm{Hg}$, in the $\mathrm{HF}$ and noHF groups. In the control group, the lungs were evaluated (first and second) at a pulmonary flow of $40 \mathrm{~mL} / \mathrm{kg}$ (Table E1).

As pilot studies indicated, a gradual increase in pulmonary vascular resistance occurred during the course of EVLP reconditioning; $15 \mathrm{mg}$ of nitroglycerin was added to the circulating perfusate of the HF and noHF groups after the second evaluation; and measurements again were made at 15 minutes, to evaluate the reversibility of this increase. A collapse test was performed in conjunction with the disconnection of the tracheal tube. Lung collapse was classified, subjectively, as normal or impaired, by the same investigator in all cases. The lungs were then weighed.

\section{Calculations}

Cardiac output in vivo, and pulmonary flow ex vivo, was indexed to body surface area $\left(\mathrm{m}^{2}\right)$, which was calculated ${ }^{8}$ as: $734 \times$ body weight $^{0.656}$ $(\mathrm{kg}) / 10,000$. The pulmonary vascular resistance index was calculated as: [(mean pulmonary artery pressure - pulmonary capillary wedge pressure)/cardiac index], in vivo; and [mean pulmonary artery pressure/pulmonary flow index], ex vivo. The total compliance of the respiratory system was calculated as: [(inspiratory airway plateau pressure - end-expiratory airway pressure)/tidal volume].

The oxygen content of pulmonary capillary, arterial, and mixed venous blood was calculated by the formula:

$$
1.34 \times \mathrm{Hb}(\mathrm{g} / \mathrm{l}) \times \mathrm{SO}_{2}(\%) \times 0.01+\left(0.23 \times \mathrm{PO}_{2}\right),
$$

where $\mathrm{SO}_{2}=$ oxygen saturation, and $\mathrm{PO}_{2}=$ oxygen partial pressure $(\mathrm{kPa})$ For calculation of pulmonary capillary $\mathrm{O}_{2}$, alveolar $\mathrm{PO}_{2}$ was estimated using the simplified alveolar gas equation, assuming an atmospheric pressure of $101 \mathrm{kPa}$ and a saturated vapor pressure of water at body temperature and the prevailing atmospheric pressure $\left(\mathrm{PH}_{2} \mathrm{O}\right)$ of $6.25 \mathrm{kPa}$. Intrapulmonary shunt fraction was calculated by the shunt equation dead space ratio $(\mathrm{Qs} / \mathrm{Qt})=\left(\right.$ pulmonary capillary $\mathrm{O}_{2}-$ arterial $\left.\mathrm{O}_{2}\right) /$ (pulmonary capillary $\mathrm{O}_{2}-$ mixed venous $\mathrm{O}_{2}$ ). Dead space ratio was calculated using the formula dead space ratio $(\mathrm{Vd} / \mathrm{Vt})=\left(\right.$ left atrial $\mathrm{CO}_{2}-$ endtidal $\mathrm{CO}_{2}$ )/left atrial $\mathrm{CO}_{2}$. The transpulmonary oxygen gradient ratio 


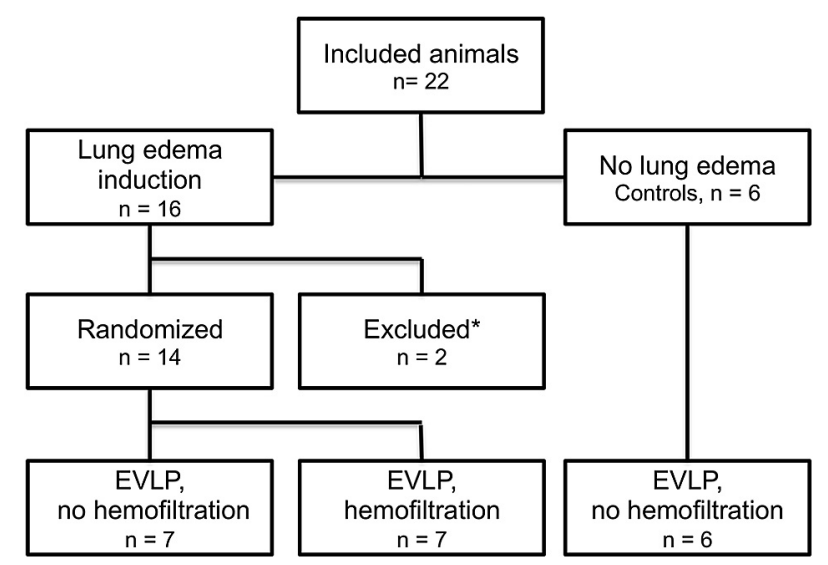

FIGURE 1. Experimental profile. *Two animals were excluded because they developed severe right heart failure during edema induction, and subsequently, target levels for pulmonary capillary wedge pressure could not be maintained. $E V L P$, Ex vivo lung perfusion.

$\left(\triangle \mathrm{Po}_{2} / \mathrm{FIO}_{2}\right)$ (ie, the ratio of the $\mathrm{Po}_{2}$ difference (left atrial - pulmonary artery $\mathrm{Po}_{2}$ ) to the $\mathrm{FIO}_{2}$, and the left atrial $\mathrm{Po}_{2} / \mathrm{FIO}_{2}$ ratio, were calculated. All arterial blood gas measurements were performed at an $\mathrm{FiO}_{2}$ of 0.5 .

\section{Statistics}

Continuous data are presented as mean $\pm \mathrm{SD}$. Changes within groups were assessed by Wilcoxon's signed-rank test. The relative changes of the variables induced by the HF group and the noHF group were compared

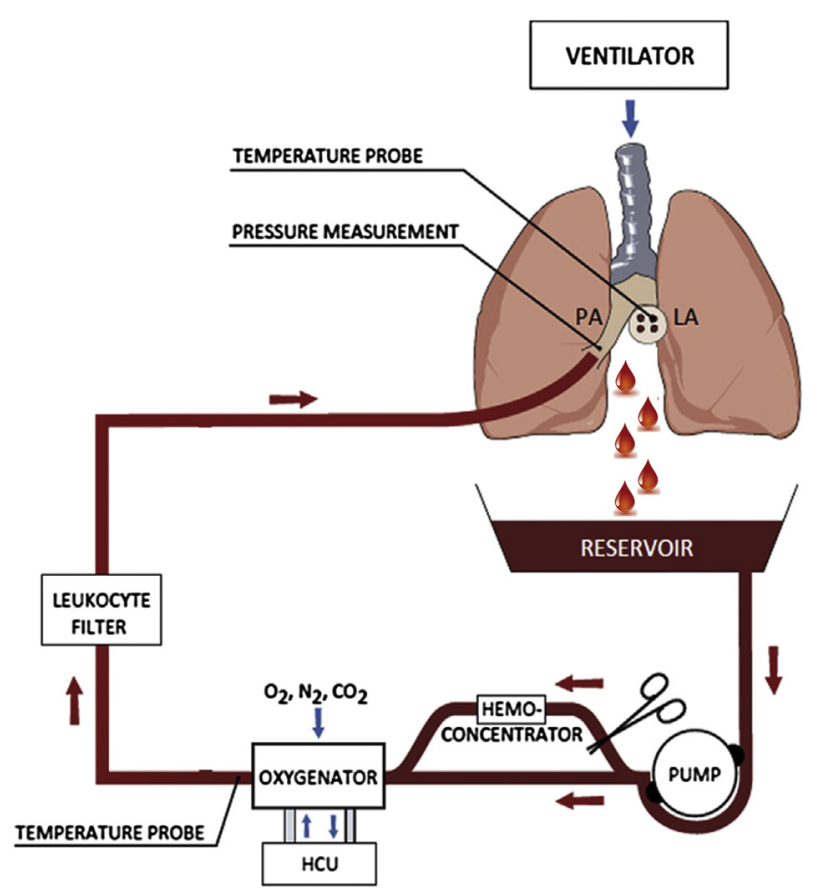

FIGURE 2. Schematic drawing of the EVLP unit with hemofiltration. The blood enters the open reservoir via the remnant of the LA. Samples for blood gas analyses are drawn from the pulmonary vein outflow and from a port after the oxygenator, where drugs can be administered. The clamp on the hemofilter circuit allows for intermittent hemoconcentration. $P A$, Pulmonary artery; $L A$, left atrium; $H C U$, heater/cooler unit.
TABLE 1. Effects of lung-edema induction on pulmonary hemodynamics and lung function

\begin{tabular}{|c|c|c|c|}
\hline Factor & Before edema & After edema & $P$ value \\
\hline Iean arterial pressure $(\mathrm{mm} \mathrm{Hg})$ & $66.8 \pm 18.6$ & $48.9 \pm 12.2$ & .004 \\
\hline $\begin{array}{l}\text { Mean pulmonary arterial } \\
\text { pressure }(\mathrm{mm} \mathrm{Hg})\end{array}$ & $15.4 \pm 4.7$ & $31.1 \pm 5.3$ & .001 \\
\hline $\begin{array}{l}\text { Pulmonary capillary wedge } \\
\text { pressure }(\mathrm{mm} \mathrm{Hg})\end{array}$ & $8.3 \pm 2.0$ & $24.6 \pm 3.2$ & .001 \\
\hline Cardiac index $\left(\mathrm{L} / \mathrm{min} / \mathrm{m}^{2}\right)$ & $4.9 \pm 1.1$ & $3.5 \pm 1.4$ & .004 \\
\hline $\begin{array}{l}\text { Pulmonary vascular resistance } \\
\text { index }\left([\text { dynes } \times \mathrm{s}] / \mathrm{cm}^{5} / \mathrm{m}^{2}\right)\end{array}$ & $181 \pm 114$ & $294 \pm 218$ & .005 \\
\hline Arterial saturation $(\%)$ & $97.3 \pm 0.8$ & $85.5 \pm 15.3$ & .001 \\
\hline $\begin{array}{l}\text { Arterial } \mathrm{CO}_{2} \text { partial } \\
\text { pressure }(\mathrm{kPa})\end{array}$ & $4.80 \pm 0.52$ & $5.62 \pm 1.13$ & .013 \\
\hline Arterial pH & $7.42 \pm 0.06$ & $7.31 \pm 0.08$ & .001 \\
\hline $\mathrm{PaO}_{2} / \mathrm{FIO}_{2}\left(\mathrm{FIO}_{2} 0.5\right)$ & & $25.4 \pm 13.9$ & .001 \\
\hline Compliance $\left(\mathrm{mL} / \mathrm{cm} \mathrm{H}_{2} \mathrm{O}\right)$ & $33.0 \pm 3.2$ & $27.6 \pm 3.0$ & .001 \\
\hline
\end{tabular}

Data are expressed as mean $\pm \mathrm{SD}$. $\mathrm{PaO}_{2} / \mathrm{F}_{\mathrm{IO}}$, Arterial oxygen tension indexed to fraction of inspired oxygen.

using the Mann-Whitney $U$ test. Correlations between variables were evaluated using the Pearson correlation coefficient.

\section{RESULTS}

Two animals were excluded because they developed severe right heart failure during edema induction, and subsequently, target levels for pulmonary capillary wedge pressure could not be maintained. No differences were found between the $\mathrm{HF}$ and noHF groups (both $\mathrm{n}=7$ ) in body weight $(\mathrm{kg}): 42.6 \pm 3.4$ versus $43.6 \pm 3.3$, respectively; or body surface area $\left(\mathrm{m}^{2}\right): 0.859 \pm 0.046$ versus $0.873 \pm 0.043$, respectively. The experimental profile is outlined in Figure 1.

\section{Pulmonary-Edema Induction}

The induction of pulmonary edema caused a decrease in oxygen saturation and arterial $\mathrm{Po}_{2}$, a decrease in $\mathrm{Po}_{2} / \mathrm{FiO}_{2}$ ratio, an increase in arterial $\mathrm{PCO}_{2}$ and PVRI. Static lung compliance decreased, by a mean of $16 \%$. No significant differences were found between the noHF and the HF groups at the end of edema induction with respect to oxygen saturation $(P=.456)$, arterial $\mathrm{Po}_{2}(P=.366)$, arterial $\mathrm{PCO}_{2}$ $(P=1.0)$, the left atrial $\mathrm{Po}_{2} / \mathrm{FIO}_{2}$ ratio $(P=.366)$, compliance $(P=.209)$, the dead space ratio $(P=.476)$, or PVRI $(P=.620)$ (Table 1$)$. Lung weight, lung weight $/ \mathrm{kg}$ body weight, and lung weight/body surface area, after edema induction and lung harvesting, were: $651 \pm 97 \mathrm{~g}, 15.2 \pm 2.6 \mathrm{~g} /$ $\mathrm{kg}$, and $755 \pm 119 \mathrm{~g} / \mathrm{m}^{2}$, respectively, with no difference in lung weights between the noHF and HF groups $(P=.81$ 1.0) (Table 3).

\section{Ex Vivo Lung Perfusion}

At the first evaluation, compared with in vivo values after pulmonary-edema induction, the left atrial $\mathrm{PO}_{2} / \mathrm{FIO}_{2}$ ratio increased considerably during EVLP ( $\mathrm{kPa} ; 25.4 \pm 13.9$ vs 
TABLE 2. Effects of 3 hours of EVLP reconditioning on lung function, perfusate oncotic pressure, and lung weight

\begin{tabular}{|c|c|c|c|c|c|c|c|}
\hline \multirow[b]{2}{*}{ Measure } & \multicolumn{2}{|c|}{ Control group $(n=6)$} & \multicolumn{2}{|c|}{ No HF $(n=7)$} & \multicolumn{2}{|c|}{ HF $(n=7)$} & \multirow{2}{*}{$\frac{\text { HF vs no HF }}{P \text { value }}$} \\
\hline & First & Second & First & Second & First & Second & \\
\hline Left atrial $\mathrm{Po}_{2} / \mathrm{FIO}_{2}\left(\mathrm{FIO}_{2}: 0.5\right)(\mathrm{kPa})$ & $56.5 \pm 9.5$ & $55.8 \pm 12.1$ & $51.9 \pm 12.5$ & $46.1 \pm 12.9$ & $54.1 \pm 15.0$ & $54.2 \pm 7.3$ & .62 \\
\hline$\Delta \mathrm{Po}_{2} / \mathrm{FIO}_{2}\left(\mathrm{FIO}_{2}: 0.5\right)(\mathrm{kPa})$ & $50.5 \pm 9.3$ & $47.2 \pm 15.7$ & $44.8 \pm 12.9$ & $41.3 \pm 13.8$ & $46.3 \pm 14.4$ & $48.9 \pm 7.0$ & .81 \\
\hline Compliance $\left(\mathrm{mL} / \mathrm{cm} \mathrm{H}_{2} 0\right)$ & $57 \pm 12$ & $45 \pm 10^{*}$ & $52.3 \pm 11.4$ & $27.8 \pm 5.7^{*}$ & $60.4 \pm 23.6$ & $44.8 \pm 19.5^{*}$ & .038 \\
\hline PVRI ([dynes $\left.\times \mathrm{s}] / \mathrm{cm}^{5} / \mathrm{m}^{2}\right)$ & $584 \pm 152$ & $978 \pm 181^{*}$ & $433 \pm 257$ & $996 \pm 502$ & $338 \pm 95$ & $910 \pm 610^{*}$ & 1.00 \\
\hline Dead space fraction & $0.229 \pm 0.121$ & $0.173 \pm 0.066$ & $0.067 \pm 0.102$ & $0.196 \pm 0.067^{*}$ & $0.076 \pm 0.162$ & $0.121 \pm 0.108$ & .71 \\
\hline Pulmonary flow index $\left(\mathrm{L} / \mathrm{min} / \mathrm{m}^{2}\right)$ & $2.2 \pm 0.1$ & $2.2 \pm 0.2$ & $5.58 \pm 1.97$ & $2.52 \pm 1.25^{*}$ & $6.2 \pm 1.20$ & $2.79 \pm 1.10^{*}$ & 1.00 \\
\hline Shunt fraction & $0.250 \pm 0.070$ & $0.219 \pm 0.100$ & $0.300 \pm 0.132$ & $0.241 \pm 0.124$ & $0.268 \pm 0.079$ & $0.190 \pm 0.054$ & 1.00 \\
\hline Perfusate oncotic pressure $(\mathrm{mm} \mathrm{Hg})$ & $28.5 \pm 1.3$ & $34.4 \pm 1.1^{*}$ & $28.5 \pm 1.8$ & $31.7 \pm 2.3^{*}$ & $29.0 \pm 1.1$ & $41.6 \pm 3.3^{*}$ & .001 \\
\hline Perfusate hematocrit $(\%)$ & $13.5 \pm 1.5$ & $15.4 \pm 1.9^{*}$ & $10.5 \pm 1.7$ & $10.6 \pm 2.0$ & $10.7 \pm 2.2$ & $13.5 \pm 2.6^{*}$ & .001 \\
\hline Lung weight $(\mathrm{g})$ & $430 \pm 27$ & $540 \pm 92^{*}$ & $647 \pm 114$ & $663 \pm 105$ & $655 \pm 87$ & $556 \pm 72 *$ & .038 \\
\hline
\end{tabular}

Data are expressed as mean $\pm \mathrm{SD}$. First and second indicate evaluation phase. $\Delta \mathrm{Po}_{2}=$ left atrial $\mathrm{PO}_{2}-$ pulmonary artery $\mathrm{Po}_{2} H F$, $\mathrm{Hemofiltration} ; F_{I O}$, inspired fraction of oxygen; $\mathrm{PO}_{2}$, oxygen tension; $P V R I$, pulmonary vascular resistance index; $B W$, body weight. ${ }^{*} P<.05$ at second versus first evaluation. $\dagger$ Relative changes between first and second evaluation in the HF versus noHF groups.

$53.0 \pm 13.3$, respectively: $P<.001)$; and oxygen saturation $(85.5 \% \pm 15.3 \%$ vs $99.9 \% \pm 0.3 \%$, respectively; $P<.001)$; whereas dead space ratio did not change significantly $(0.137 \pm 0.191$ vs $0.071 \pm 0.130$, respectively; $P=.721)$.

Hemofiltration during the reconditioning phase significantly increased the oncotic pressures of the perfusate by $43 \%(P=.018)$ and the hematocrit by $26 \%(P=.018)$. In the noHF group, a minor increase occurred in oncotic pressures $(11 \%)$; the hematocrit was unchanged. Hemofiltration caused a significant decrease of $15 \%(P<.05)$ in lung weight; no significant change was found in the noHF group.

Lung compliance decreased in both groups during reconditioning $(P<.05)$, but the decrease was less pronounced in the $\mathrm{HF}$ group $(P<.05)$. The $\Delta \mathrm{Po}_{2} / \mathrm{FIO}_{2}$ ratio, left atrial $\mathrm{Po}_{2} /$ $\mathrm{FIO}_{2}$ ratio, shunt fraction or arterial oxygen saturation were not different between the groups. Dead space fraction increased in both groups with no significant difference between the groups. Both groups had a $55 \%$ decrease in pulmonary flow index, and a 2.3- to 2.7-fold increase in PVRI, with no significant differences between the groups. All lungs developed consolidation of the inferior lobes (impaired collapse test). A close correlation was found, of both left atrial $\mathrm{Po}_{2} / \mathrm{FIO}_{2}$ and $\Delta \mathrm{Po}_{2} / \mathrm{FIO}_{2}$ with intrapulmonary shunt fraction ( $r=0.71$ and $r=0.78$, respectively) (Table 2).
Nitroglycerin decreased PVRI in the noHF and HF groups, by $45 \%$ and $35 \%$, respectively, and increased pulmonary flow by $88 \%$ and $82 \%$, respectively. Nitroglycerin impaired lung oxygenation capacity, as demonstrated by a $15 \%$ to $20 \%$ decrease in the $\mathrm{PaO}_{2} / \mathrm{FIO}_{2}$ ratio in both groups, as well as a decrease in $\Delta \mathrm{Po}_{2} / \mathrm{FIO}_{2}$ by $19 \%$ to $26 \%$ in both groups. Intrapulmonary shunt fraction increased by $61 \%$ to $65 \%$, in both groups, with nitroglycerin.

\section{Control Group}

The lung weight of the control group (no edema, no HF) increased significantly, by $26 \%(P=.046)$ during EVLP. In the control group, lung compliance decreased by $21 \%$ $(P=.028)$, and PVRI increased by $67 \%(P=.028)$. Oncotic pressures and hematocrit increased by $20 \%$ $(P=.027)$ and 14\% $(P=.028)$, respectively. The left atrial $\mathrm{Po}_{2} / \mathrm{FIO}_{2}$ ratio, the $\Delta \mathrm{Po}_{2} / \mathrm{FIO}_{2}$ ratio, arterial oxygen saturation, and the shunt fraction and dead space fraction were not affected by EVLP (Table 3).

\section{DISCUSSION}

In this study, we evaluated the feasibility of HF during EVLP for treatment of experimentally induced lung edema. By incorporating a hemofilter in the EVLP circuit, we were able to increase the perfusate oncotic pressure by $40 \%$ to $45 \%$. This increase was accompanied by a $15 \%$ decrease

TABLE 3. Effects of nitroglycerin on lung function after reconditioning

\begin{tabular}{|c|c|c|c|c|c|}
\hline & \multicolumn{2}{|c|}{ NoHF } & \multicolumn{2}{|c|}{ HF } & \multirow{2}{*}{$\frac{\text { noHF vs HF }}{P \text { value }}$} \\
\hline & Second evaluation & After nitroglycerin & Second evaluation & After nitroglycerin & \\
\hline Left atrial $\mathrm{Po}_{2} / \mathrm{FIO}_{2}\left(\mathrm{FIO}_{2}: 0.5\right)(\mathrm{kPa})$ & $46.1 \pm 12.9$ & $36.9 \pm 8.6$ & $54.2 \pm 7.3$ & $46.2 \pm 7.8^{*}$ & .46 \\
\hline$\Delta \mathrm{Po}_{2} / \mathrm{FIO}_{2}\left(\mathrm{FIO}_{2}: 0.5\right)(\mathrm{kPa})$ & $41.3 \pm 13.8$ & $30.7 \pm 9.2^{*}$ & $48.9 \pm 7.0$ & $39.7 \pm 7.6^{*}$ & .46 \\
\hline PVRI $\left([\right.$ dynes $\left.\times \mathrm{s}] / \mathrm{cm}^{5} / \mathrm{m}^{2}\right)$ & $996 \pm 502$ & $544 \pm 206^{*}$ & $910 \pm 610$ & $588 \pm 437^{*}$ & .71 \\
\hline Dead space fraction & $0.196 \pm 0.067$ & $0.150 \pm 0.139$ & $0.121 \pm 0.108$ & $0.023 \pm 0.101^{*}$ & .053 \\
\hline Pulmonary flow index $\left(\mathrm{L} / \mathrm{min} / \mathrm{m}^{2}\right)$ & $2.52 \pm 1.25$ & $4.70 \pm 1.31^{*}$ & $2.79 \pm 1.10$ & $5.08 \pm 1.95^{*}$ & .71 \\
\hline Shunt fraction & $0.241 \pm 0.124$ & $0.385 \pm 0.114 *$ & $0.190 \pm 0.054$ & $0.309 \pm 0.094 *$ & .62 \\
\hline
\end{tabular}

Data are expressed as mean $\pm \mathrm{SD} . \Delta \mathrm{PO}_{2}=$ left atrial $\mathrm{PO}_{2}$ - pulmonary artery $\mathrm{PO}_{2}$. $\mathrm{HF}$, hemofiltration; $\mathrm{FIO}_{2}$, inspired fraction of oxygen; $P O_{2}$, oxygen tension; $P V R I$, pulmonary vascular resistance index. $* P<.05$ after nitroglycerin versus second evaluation. $\dagger$ Relative changes between first and second evaluation in the $\mathrm{HF}$ versus noHF groups. 
in mean lung weight in the HF group, which was not seen in the noHF group. In both groups, static lung compliance decreased during the reconditioning phase, but the decrease was significantly less marked in the HF group.

Lung weight per kg body weight after edema induction was $106 \%$ higher in our study population, compared with the control group of animals not subjected to edema induction. This result indicates that our technique for induction of pulmonary edema was efficient, and that on average, each lung gained well more than $300 \mathrm{~mL}$ of edema in our model. The $15 \%$ loss of weight seen in the HF group corresponds to removal of approximately one third of this volume of lung water, indicating that HF was effective in dehydrating the edematous lungs in our model.

In both groups, a gradual, significant fall in compliance of the edematous lungs was seen during the reconditioning phase, despite ventilation with positive end-expiratory pressure, and lung recruitment every 60 minutes. The finding that lung weight during this phase was, respectively, unchanged and decreased, in the noHF and HF groups, suggests that the major contributor to this fall in lung compliance was the development of atelectatic consolidations, which may explain why lung oxygenation capacity was not improved in the HF group, despite HF-induced dehydration.

A fall in lung compliance has been described during experimental EVLP of lungs injured by 24 hours of cold ischemia. ${ }^{9}$ In the supine position, the degree of lung inflation at a certain level along the ventro-dorsal axis is dependent on the weight of the lung tissue compressing it from above. Thus, the dependent lung regions are more compressed than the ventral portions. "Heavy" edematous lungs reinforce such a vertical gradient of regional lung inflation, ${ }^{10}$ as shown in the present study. Such a vertical gradient may be accentuated during ventilation ex vivo, compared with in vivo, when a negative pleural pressure surrounds the lungs.

When the injured edematous lungs were ventilated and recruited, ex vivo, the lung oxygenation capacity improved considerably before the reconditioning phase started. Three hours of reconditioning with positive end-expiratory pressure and intermittent recruitment maneuvers did not improve the lung oxygenation capacity further, not even in the HF group. Thus, the main improvement of lung oxygenation capacity in this animal model of lung edema was seen early after initiation of EVLP; in the ex vivo situation, ventilation with positive end-expiratory pressure, plus a recruitment maneuver, allows an optimal alveolar reopening to occur, as opposing forces for alveolar expansion (abdominal pressure, chest wall stiffness) are eliminated. Such a significant increase in the left atrial $\mathrm{PO}_{2} / \mathrm{FIO}_{2}$ ratio in the early period $(\leq 1$ hour) of clinical EVLP has been described, with no further improvement after 4 hours of EVLP. $^{3,11}$
Theoretically, one advantage of EVLP reconditioning is to mobilize alveolar and/or interstitial fluid from edematous lungs using a hyperoncotic solution. However, the mean lung weight of the noHF group was not affected by 3 hours of reconditioning, suggesting that the perfusate was not effective in decreasing the degree of lung water in the edematous lungs during reconditioning. In fact, the oncotic pressure increased during reconditioning in the noHF group, suggesting a transfer of fluid from the perfusate of the EVLP circuit to the edematous and injured lungs, a phenomenon seen as well in the control group that was not subjected to injury/edema.

These results are in line with our clinical EVLP experiences, which show that nonedematous lungs may gain weight during a 2.5- to 3-hour EVLP, using the same technique as that in this study. ${ }^{4,12}$ Furthermore, Pierre and colleagues $^{13}$ showed, in an experimental pig model of noninjured lungs, that EVLP for 2.5 hours increased lung weight by $23 \%$, probably as a result of reperfusion injury of the lung graft. Such injury was confirmed in the present study, in which the lung weight of the noninjured control group increased by $25 \%$, accompanied by a decrease in lung compliance. Therefore, we are not convinced that EVLP reconditioning with the slightly hyperoncotic (28$29 \mathrm{~mm} \mathrm{Hg}$ ) Steen solution specifically contributes to the improved lung oxygenation capacity seen in clinical EVLP. ${ }^{4,12,14}$

In the edematous lungs, a 2.3- to 2.7-fold increase occurred in PVRI during EVLP. This finding may be explained, at least partly, by a hypoxic pulmonary vasoconstrictive response. This increase in PVRI was not attenuated by HF, as this procedure did not attenuate the degree of alveolar hypoxia of the injured lungs. Furthermore, the presence of red blood cells, in contrast to acellular solutions, may have augmented this pulmonary hypoxic vasoconstrictor response, owing to inactivation of nitric oxide by red blood cell hemoglobin. ${ }^{15}$ Moreover, our EVLP technique, along with the cell saver-processed blood, may have caused hemolysis with increasing levels of free hemoglobin during the reconditioning phase. Free hemoglobin has a high affinity for the endogenous vasodilator nitric oxide. Scavenging of nitric oxide by free hemoglobin will limit the bioavailability of nitric oxide, and thus induce pulmonary vasoconstriction. ${ }^{15}$ Perfusion of isolated lungs with low concentrations of free hemoglobin has been shown to induce a substantial hypoxic vasoconstrictor response. ${ }^{16}$

Introduction of a nitric oxide donor, nitroglycerin, to the perfusate at the end of the reconditioning phase, reduced the elevated PVRI by $35 \%$ to $45 \%$, and alleviated the hypoxic vasoconstrictor response in both the noHF and HF groups, suggesting that an interaction among red blood cells, hemoglobin, and nitric oxide may be of importance for the pulmonary vasoconstrictor response during reconditioning of the 
injured edematous lungs. This interaction may explain the significant increase of PVRI in the noninjured control group.

The left atrial $\mathrm{Po}_{2} / \mathrm{FIO}_{2}$ ratio is extensively used in the evaluation of lung function in patients with acute lung injury, because of its simplicity. In vivo, this ratio depends on the $\mathrm{FIO}_{2}$, the intrapulmonary shunt fraction, and mixed venous oxygen content. ${ }^{17}$ The question has been raised of whether the left atrial $\mathrm{Po}_{2} / \mathrm{FIO}_{2}$ ratio can provide sufficient evaluation of oxygenation capacity during EVLP. A suggestion for a better variable for this purpose is $\triangle \mathrm{Po}_{2}$, because it accounts for variations in the oxygen content of the arterial inflow, which affects the left atrial $\mathrm{PO}_{2} / \mathrm{FIO}_{2}$ ratio. ${ }^{18}$

In this study, we calculated both the left atrial $\mathrm{Po}_{2} / \mathrm{FIO}_{2}$ ratio, and the $\Delta \mathrm{Po}_{2} / \mathrm{FIO}_{2}$ ratio, and found that both were closely correlated with the intrapulmonary shunt fraction, with $r=0.71$ and $r=0.78$, respectively. Given this correlation, both variables can be used to assess the degree of ventilation/perfusion mismatch, and therefore, the degree of lung injury. In contrast, analyses of blood gas in an acellular perfusate during EVLP cannot be used to reliably detect impaired lung functioning, particularly in the case of a ventilation/perfusion mismatch. ${ }^{9}$ Therefore, in accordance with the EVLP protocol originally described by Wallinder and colleagues, ${ }^{4,12}$ we continue to evaluate lungs using blood gas analysis at a high pulmonary artery-pressure limit, with full ventilation, and with red blood cells in the perfusate.

\section{Limitations}

One limitation of the present study is that the performance of the edematous lungs was assessed only during EVLP and was not tested in vivo after transplantation. Thus, we do not know whether the HF-induced beneficial effect on lung compliance and lung weight during EVLP translates into improved oxygenation in vivo after transplantation. On the other hand, in the clinical setting, surgeons would be more inclined to transplant lungs with less edema. In addition, restoration of negative pleural pressure, in vivo, may facilitate lung recruitment in the dependent lung regions, particularly after prior treatment of lung edema by HF during EVLP.

\section{CONCLUSIONS}

We have shown that, in this lung-edema model, EVLP reconditioning with Steen solution, without HF, did not affect the degree of lung edema. In contrast, HF during EVLP increased perfusate oncotic pressure, resulted in edema reduction, and hence decreased lung weight. In addition, HF had beneficial effects on compliance, compared with the control group, but it did not improve lung oxygenation capacity. Further experimental and/or clinical studies would be valuable, to determine whether the demonstrated edemareducing properties of HF during EVLP translate into improved lung-oxygenation capacity and compliance in vivo.

\section{Conflict of Interest Statement}

Authors have nothing to disclose with regard to commercial support.

The authors thank all the dedicated staff at the Laboratory for Experimental Biomedicine at Gothenburg University.

\section{References}

1. Steen S, Ingemansson R, Eriksson L, Pierre L, Algotsson L, Wierup P, et al. First human transplantation of a nonacceptable donor lung after reconditioning ex vivo. Ann Thorac Surg. 2007;83:2191-4.

2. Aigner C, Slama A, Hotzenecker K, Scheed A, Urbanek B, Schmid W, et al. Clinical ex vivo lung perfusion_-pushing the limits. Am J Transplant. 2012;12:1839-47.

3. Cypel M, Yeung JC, Machuca T, Chen M, Singer LG, Yasufuku K, et al. Experience with the first 50 ex vivo lung perfusions in clinical transplantation. $J$ Thorac Cardiovasc Surg. 2012;144:1200-6.

4. Wallinder A, Ricksten SE, Hansson C, Riise GC, Silverborn M, Liden H, et al. Transplantation of initially rejected donor lungs after ex vivo lung perfusion. $J$ Thorac Cardiovasc Surg. 2012;144:1222-8.

5. Cypel M, Yeung JC, Hirayama S, Rubacha M, Fischer S, Anraku M, et al. Technique for prolonged normothermic ex vivo lung perfusion. J Heart Lung Transplant. 2008;27:1319-25.

6. Wallinder A, Hansson C, Dellgren G. Hemoconcentration in ex vivo lung perfusion: a case report of a novel technique used in clinical lung transplantation. $J$ Thorac Cardiovasc Surg. 2013;145:e76-7.

7. Wallinder A, Steen S, Liden H, Hansson C, Hussein AA, Sjoberg T, et al. Heparin does not improve graft function in uncontrolled non-heart-beating lung donation: an experimental study in pigs. Eur J Cardiothorac Surg. 2013;43:413-9.

8. Kelley KW, Curtis SE, Marzan GT, Karara HM, Anderson CR. Body surface area of female swine. J Anim Sci. 1973;36:927-30.

9. Yeung JC, Cypel M, Machuca TN, Koike T, Cook DJ, Bonato R, et al. Physiologic assessment of the ex vivo donor lung for transplantation. J Heart Lung Transplant. 2012;31:1120-6.

10. Pelosi P, D'Andrea L, Vitale G, Pesenti A, Gattinoni L. Vertical gradient of regional lung inflation in adult respiratory distress syndrome. Am J Respir Crit Care Med. 1994;149:8-13.

11. Cypel M, Yeung JC, Liu M, Anraku M, Chen F, Karolak W, et al. Normothermic ex vivo lung perfusion in clinical lung transplantation. N Engl J Med. 2011;364: 1431-40.

12. Wallinder A, Ricksten SE, Silverborn M, Hansson C, Riise GC, Liden H, et al. Early results in transplantation of initially rejected donor lungs after ex vivo lung perfusion: a case-control study. Eur J Cardiothorac Surg. 2014;45:40-4; discussion 44-5.

13. Pierre L, Lindstedt S, Hlebowicz J, Ingemansson R. Is it possible to further improve the function of pulmonary grafts by extending the duration of lung reconditioning using ex vivo lung perfusion? Perfusion. 2013;28:322-7.

14. Ingemansson R, Eyjolfsson A, Mared L, Pierre L, Algotsson L, Ekmehag B, et al Clinical transplantation of initially rejected donor lungs after reconditioning ex vivo. Ann Thorac Surg. 2009;87:255-60.

15. Deem S, Kim SS, Min JH, Eveland R, Moulding J, Martyr S, et al. Pulmonary vascular effects of red blood cells containing S-nitrosated hemoglobin. Am J Physiol Heart Circ Physiol. 2004;287:H2561-8.

16. Deem S, Berg JT, Kerr ME, Swenson ER. Effects of the RBC membrane and increased perfusate viscosity on hypoxic pulmonary vasoconstriction. $J$ Appl Physiol. 2000;88:1520-8.

17. Aboab J, Louis B, Jonson B, Brochard L. Relation between $\mathrm{PaO} / \mathrm{FIO}_{2}$ ratio and $\mathrm{FIO}_{2}$ : a mathematical description. Intensive Care Med. 2006;32:1494-7.

18. Aigner C. Editorial comment: Growing experience with ex vivo lung perfusion: many ways leading to the same goal. Eur J Cardiothorac Surg. 2014; $45: 45-6$.

Key Words: ex vivo lung perfusion, lung edema, lung reconditioning, hemofiltration 
TABLE E1. Settings during the phases of EVLP

Phase

\begin{tabular}{|c|c|c|c|c|c|c|}
\hline & & & & & & \\
\hline Setting & & Rewarming & & First evaluation & Reconditioning & Second evaluation \\
\hline Lung temperature $\left({ }^{\circ} \mathrm{C}\right)$ & -32 & $32-34$ & $34-36$ & 36 & 36 & 36 \\
\hline EVLP device phase* & Reconditioning & Reconditioning & Reconditioning & Evaluation & Reconditioning & Evaluation \\
\hline PA pressure $(\mathrm{mm} \mathrm{Hg})$ & 15 & 15 & 15 & 25 & 25 & 25 \\
\hline PA flow range $(\mathrm{mL} / \mathrm{kg} \mathrm{BW} / \mathrm{min}) \dagger$ & $4-8$ & $6-12$ & $10-20$ & $\operatorname{Max}$ & $20-40$ & $\operatorname{Max}$ \\
\hline $\begin{array}{l}\text { Ventilation }\left(\mathrm{cm} \mathrm{H}_{2} 0\right)\left(\mathrm{FIO}_{2}: 0.5 \text {, positive }\right. \\
\text { end-expiratory pressure: } 5)\end{array}$ & & & & & & \\
\hline Mode & - & PC & $\mathrm{VC}$ & VC & $\mathrm{VC}$ & $\mathrm{VC}$ \\
\hline Peak inspiratory pressure/tidal volume & - & $12 \mathrm{~mm} \mathrm{Hg}$ & $12 \mathrm{~mm} \mathrm{Hg}$ & $6 \mathrm{~mL} / \mathrm{kg} \mathrm{BW}$ & $6 \mathrm{~mL} / \mathrm{kg} \mathrm{BW}$ & $6 \mathrm{~mL} / \mathrm{kg} \mathrm{BW}$ \\
\hline Respiratory frequency & - & 7 & 7 & 10 & $\begin{array}{l}\text { Adjusted to obtain } \\
\text { MV } 1.5 \times \text { PA flow }\end{array}$ & 10 \\
\hline $\begin{array}{l}\text { Lung recruitment (positive end- } \\
\text { expiratory pressure, } 15 \mathrm{~mm} \mathrm{Hg} \text { ) }\end{array}$ & - & - & - & $\begin{array}{l}\text { At start of } \\
\text { evaluation }\end{array}$ & Every $60 \mathrm{~min}$ & $\begin{array}{l}\text { At start of } \\
\text { evaluation }\end{array}$ \\
\hline
\end{tabular}

